\title{
IMPLEMENTASI CHATBOT UNTUK MENDUKUNG SISTEM INFORMASI PADA RUMAH SAKIT MUHAMADIYAH PALEMBANG
}

\author{
Eldi $^{1}$, Hadi Syaputra ${ }^{2}$ \\ ${ }^{1,2}$ Fakultas Teknik Ilmu Komputer, Universitas Bina Darma, Palembang, Indonesia \\ Email : eldiganteng06@gmail.com¹, hadisyaputra@binadarma.ac.id ${ }^{2}$
}

\begin{abstract}
Communication technology has now experienced very rapid development and is increasingly sophisticated. With the existence of a web-based information system, now it can not only be used as a medium for long distance conversations and sending short messages. With this web information system, it can be used to access the internet faster and can also be used as a medium of information that is always updated. The rapid development of information technology lately has entered almost all areas of life, this is indicated by the large number of computer users, both for corporate or business interests, to matters of entertainment, education and health. Muhammadiyah Rs Palembang is one of the health service institutions that organizes complete individual health services that provide inpatient, outpatient and emergency services. The development of a chatbot information system at Rs Muhammadiyah Palembang was carried out to make it easier for patients to find out about Rs. Service information such as the number of available patient rooms. The process of developing the chatbot information system uses the Unified Process (UP) method. With the availability of faster information, it is hoped that it will make it easier for patients to find out about services at Muahmmadiyah Hospital Palembang.
\end{abstract}

Keywords: chatbot, information system

\begin{abstract}
Abstrak
Teknologi komunikasi kini telah mengalami perkembangan yang sangat pesat dan semakin canggih Dengan adanya sistem informasi berbasis web , sekarang tidak hanya dapat digunakan sebagai media untuk berbicara jarak jauh dan mengirim pesan singkat. Dengan adanya sistem informasi web ini dapat dimanfaatkan untuk mengakses internet lebih cepat dan juga dapat digunakan sebagai media informasi yang selalu update. Perkembangan teknologi informasi yang pesat belakangan ini telah memasuki hampir semua bidang kehidupan, hal ini ditandai dengan banyaknya pengguna komputer, baik untuk kepentingan perusahaan atau bisnis sampai kepada hal-hal yang bersifat hiburan, pendidikan dan kesehata. Rs Muhammadiyah palembang adalah salah satu institusi pelayanan kesehatan yang menyelenggarakan pelayanan kesehatan perorangan secara paripurna yang menyediakan pelayanan rawat inap, rawat jalan dan gawat darurat. Pembuatan Sistem informasi chatbot di Rs Muhammadiyah Palembang dilakukan untuk mempermudah pasien mengetahui tentang informasi pelyanan Rs.Seperti Jumlah kamar Pasien yang tersedia. Proses pembangunan system informasi chatbot ini menggunakan metode Unified Process (UP). Dengan adanya informasi yang lebih cepat nantinya di harap kan dapat mempermudah pasien dalam mengetahui layanan pada Rs Muahmmadiyah Palembang.
\end{abstract}

Kata Kunci: Chatbot, Sistem informasi

\section{Pendahuluan}

Seiring perkembangan zaman, secara implikasi menunjang perkembangan teknologi dengan sangat pesat. Informasi adalah salah satu kata kunci pada era globalisasi pada saat ini. Semua aktivitas kehidupan akan memerlukan informasi, sehingga bisa dikatakan bahwa semua aktivitas yang dijalankan dituntut untuk menghasilkan informasi berguna bagi setiap orang (Maskur, 2016). Perkembangan teknologi informasi 
yang pesat belakangan ini telah memasuki hampir semua bidang kehidupan, hal ini ditandai dengan banyaknya pengguna komputer, baik untuk kepentingan perusahaan atau bisnis sampai kepada hal-hal yang bersifat hiburan, pendidikan dan kesehatan."Rumah sakit Muhammadiya Palembang menggunakan Teknologi Informasi untuk memberikan berbagai informasi kepada masyarakat, dengan tujuan agar masyarakat dapat mudah mengetahui informasi yang di butuhkan tentang Rumah Sakit Muhammadiyah Palembang.

Teknologi chatbotmerupakan salah satu bentuk aplikasi Natural Language Processing, NLP itu sendiri merupakan salah satu bidang ilmu Kecerdasan Buatan Artificial Intelligence yang mempelajari komunikasi antara manusia dengan komputer melalui bahasa alami. Model komputasi seperti ini berguna untuk memudahkan komunikasi antara manusia dengan komputer dalam hal pencarian informasi, sehingga dapat terjadi suatu interaksi antara keduanya dengan menggunakan bahasa alami. Aplikasi ini dibangun agar masyarakat dapat mudah mengetahui informasi yang di butuhkan tentang Rumah Sakit Muhammadiyah Palembang.

Hal tersebut yang melatar belakangipenulis ingin mengembangkan sebuah aplikasi chatbot untuk mendukung sistem informasi rumah sakit muhammadiyah palembang berbasis web sebagai media pendukung informasi "Implementasi Chatbot untuk Mendukung Sistem Infromasi pada Rumah Sakit Muhammadiya Palembang".

\section{Metodologi Penelitian}

\subsection{Metode Penelitian}

Metode penelitian yang digunakan adalah Action Research, Action Research adalah sebuah metode penelitian, didirikan atas asumsi bahwa teori dan praktik dapat secara tertutup diintegrasikan dengan pembelajaran dari hasil intervensi yang direncanakan setelah diagnosis yang rinci terhadap konteks masalahnya. Berikut ini merupakan langkah-langkah pokok dalam metode action research, yaitu (Davison, Martinsons \& Kock , 2004):

1. Melakukan diagnosa (diagnosing), Chatbot principle telah dibuat hanya dapat menangani beberapa tugas percakapan di antaranya adalah penanganan percakapan untuk melakukan pemeriksaan pasien. "Untuk kedepannya dapat dirancang chatbot principle memiliki kemampuan untuk menjawab pertanyaan terkait dengan segala aktifitas. Sehingga peran client advantage di dalam rumah sakit dapat digantikan dengan chatbot.

2. Membuat rencana tindakan (action planning), Peneliti bersama-sama memahami pokok masalah principle ADA kemudian dilanjutkan dengan menyusun rencana tindakan yang tepat untuk menyelesaikan masalah principle ADA, pada tahap ini pengembangan situs web memasuki tahapan desain situs web. Dengan memperhatikan kebutuhan partner terhadap situs web penelitian bersama partisipan memulai membuat sketsa awal dan menentukan international intelligence agency principle Kwa ditampilkan nantinya.

3. Melakukan tindakan (action taking), Peneliti dan partisipan bersama-sama mengimplementasikan rencanatindakan dengan harapan dapat menyelesaikan masalah. Selanjutnya setelah show dibuat berdasarkan sketsa dan menyesuaikanisi yang akan ditampilkan berdasarkan kebutuhan partner dilanjutkandengan mengadakan ujicoba awal secara offline kemudianmelanjutkan dengan sewa ruang di net dengan tujuan situsnet dapat ditampilkan secara online.Peneliti dan partisipan bersama-sama mengimplementasikan rencanatindakan dengan harapan dapat menyelesaikan masalah. Selanjutnya setelah show dibuat berdasarkan sketsa dan menyesuaikanisi yang akan ditampilkan berdasarkan kebutuhan partner dilanjutkandengan mengadakan ujicoba awal secara offline kemudianmelanjutkan dengan sewa ruang di net dengan tujuan situsnet dapat ditampilkan secara online.

4. Melakukan evaluasi (evaluating), Setelah masa implementasi (hobby taking) dianggap cukup kemudian peneliti bersama partisipan melaksanakan evaluasi hasil dari implementasi tersebut, dalam tahap ini dilihat bagaimana penerimaan pegguna terhadap situs net yang ditandai dengan berbagai aktivitas-aktivitas. 
5. Pembelajaran (learning), Tahap ini merupakan bagian akhir siklus yang telah dilalui dengan melaksanakan survey tahap-pertahap yang telah berakhir kemudian penelitian ini dapat berakhir. Seluruh kriteria dalam prinsip pembelajaran harus dipelajari, perubahan dalam situasi organisasi dievaluasi oleh peneliti dan dikomunikasikan kepada klien, peneliti dan klien merefleksikan terhadap hasil proyek, yang nampak akan dilaporkan secara lengkap dan hasilnya secara eksplisit dipertimbangkan dalam hal implikasinya terhadap penerapan Canonical Activity Reaserch (CAR).

\subsection{Metode Pengumpulan Data}

Untuk mendukung kebutuhan data yang dibutuhkan selama proses penelitian, penulis menggunakan beberapa metode dalam pengumpulan data, yaitu:

1. Observasi, merupakan metode pengumpulan data dimana peneliti mencatat informasi sebagaimana yang di saksikan selama penelitian.

2. Dokumentasi, merupakan suatu metode pengumpulan data dengan mencari dan mengumpulkan data tentang hal yang berkaitan dengan penelitian.

\subsection{Metode Pengembangan Perangkat Lunak}

Adapun untuk menganalisis dan perancangan perangkat lunak menggunakan paradigma perangkat lunak Sound Bound together Handle (RUP). Sound Bound together Handle (RUP) adalah pendekatan pengembangan prangkat lunak yang dilakukan berulang-ulang (iterative), fokus pada arsitektur (design centric), lebih diarahkan berdasarkan penggunaan kasus (utilize case- driven) (Rosa A. S dan M. Shalahuddin, 2018:124). RUP memiliki empat fase yaitu:

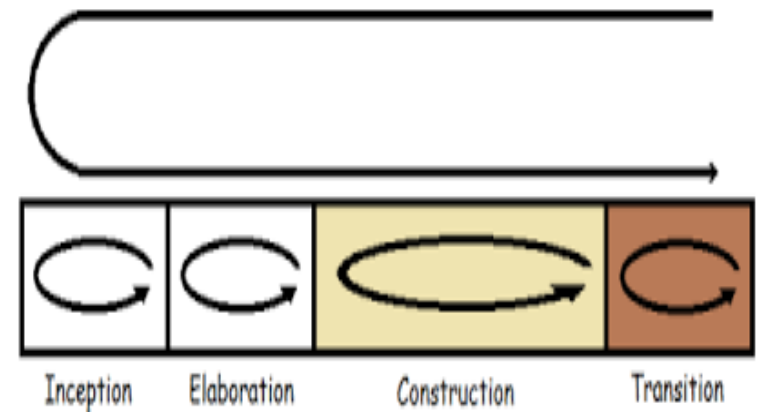

Gambar 1. Alur hidup RUP

a. Inception (permulaan), Tahap ini lebih pada memodelkan proses bisnis rule dibutuhkan (commerce modeling) dan mendefinisikan kebutuhan akan sistem yang akan dibuat (requirements).

b. Elaboration (perluasan/perencanaan), Tahap ini lebih difokuskan pada perencanaan arsitektur sistem. Tahap ini juga dapat mendeteksi apakah arsitektur sistem rule diinginkan dapat dibuat atau tidak. Mendeteksi resiko rule mungkin terjadi Iranian arsitektur yang dibuat. Tahap ini lebih pada analisis dan desain sistem serta implementasi sistem rule fokus pada purwarupa sistem (prototype).

c. Construction (konstruksi), Tahap ini fokus pada pengembangan komponen dan fitur-fitur sistem. Tahap ini lebih pada implementasi dan pengujian sistem yang center pada implementasi perangkat lunak pada kode program. Tahap ini menghasilkan produk perangkat lunak dimana menjadi syarat dari Starting Operational Capability Point of reference atau batas/tonggak kemampuan operasional awal.

d. Transition (transisi), Tahap ini lebih pada arrangement atau instalasi sistem agar dapat dimengerti oleh client. Tahap ini menghasilkan produk perangkat lunak dimana menjadi syarat dari Starting Operational Capability Turning point atau batas/tonggak kemampuan operasional sebelumnyal. Aktifitas pada tahap ini termasuk pada pelatihan client, pemeliharaan dan pengujian sistem apakah sudah memenuhi harapan user. 


\section{Hasil dan Pembahasan}

Pada bagian ini menggambarkan mengenai implementasi perancangan yang sebelumnya telah dibahas pada bagian sebelumnya. Bahasan dalam bab ini meliputi implementasi dan pengujian sistem. Implementasi dan pengujian sistem ini dilakukan untuk mengetahui apakah sistem yang telah dibangun sudah bekerja sesuai dengan rancangan sistem. Pengujian sistem dilakukan dengan menggunakan metode black-box testing. Metode ini digunakan untuk melakukan pengujian yang berfokus pada keluaran yang dihasilkan dari proses masukan yang terjadi Pada struktural laporan di bab ini, pengujian ditempatkan di dalam setiap bab implementasi dari perancangan. Terdapat beberapa implementasi yang penulis lakukan yaitu implementasi halaman login, halaman dashboard, halaman produk, halaman arrange, halaman receipt, halaman shipping yang merupakan fitur utama yang terdapat di dalam sistem pengelolaan pesanan ini dan implementasi chatbot.

\subsection{Use Case Diagram}

Use case digunakan untuk mengetahui fungsi apa saja yang ada di dalam sebuah sistem informasi dan siapa saja yang berhak menggunakan fungsi-fungsi itu. Berikut ini gambaran utilize case yang akan dibangun pada perangkat lunak.

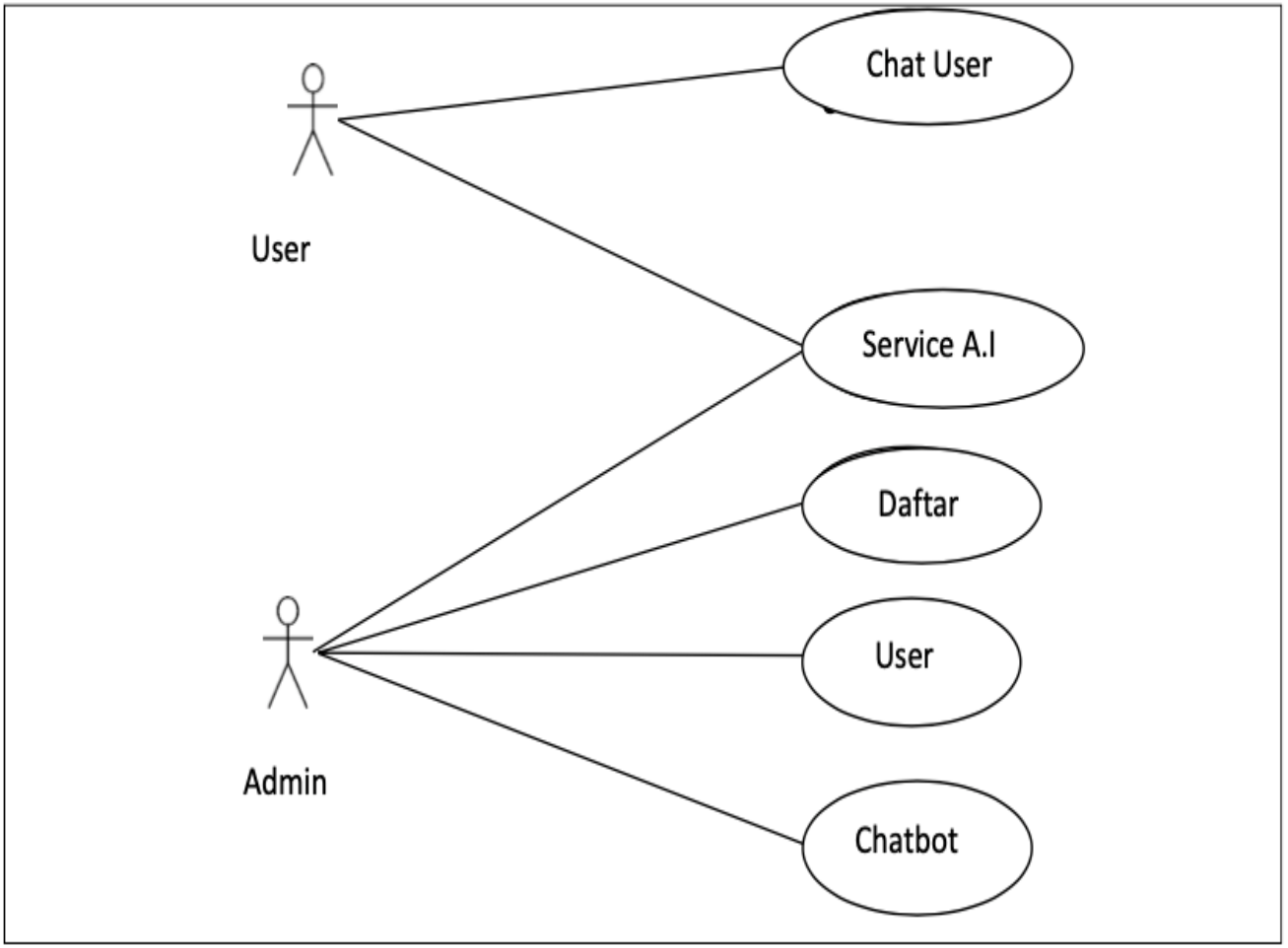

Gambar 2. Use Case Diagram

\subsection{Activity Diagram}

Action chart digunakan untuk mendefinisikan rancangan proses bisnis dimana setiap urutan aktivitas yang digambarkan merupakan proses bisnis sistem yang didefinisikan, urutan atau pengelompokan tampilan dari interface dimana setiap aktivitas dianggap memiliki sebuah rancangan antarmuka tampilan, rancangan pengujian dimana setiap aktivitas dianggap memerlukan sebuah pengujian yang perlu didefinisikan kasus ujinya dan rancangan menu yang ditampilkan pada perangkat lunak. Berikut acitivity chart yang terdapat pada perangkat lunak. 


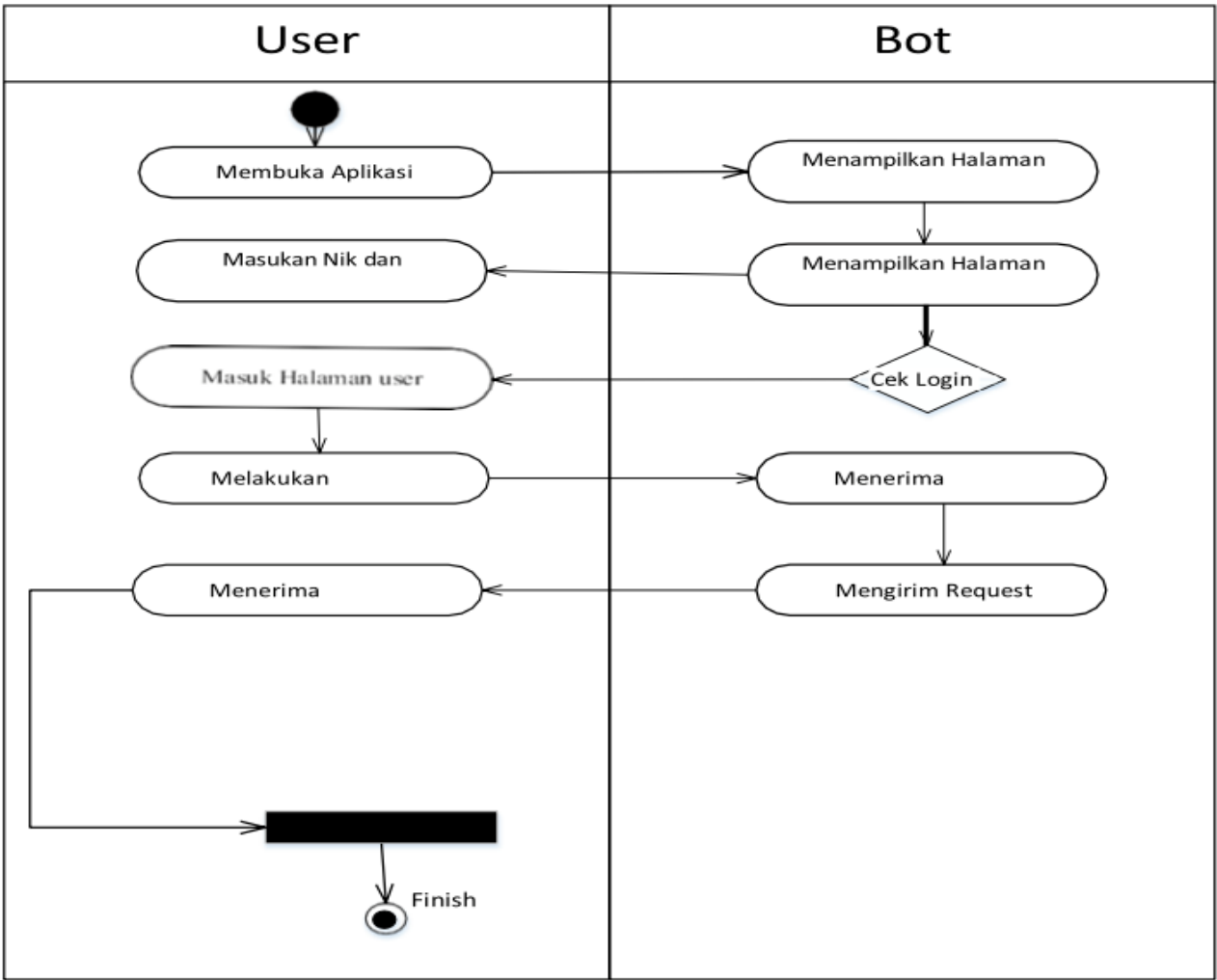

Gambar 3. Activity Diagram

\subsection{Halaman Intent DialogFlow}

Halaman ini adalah halaman yang pertama kali akan muncul pada saat membuka dialogflow di browser. Halaman intent berisi Data Training untuk melatih chatbot agar dapat menangkap apa yang kita tanyakan tentang Rs Muhammdiyah Palembang.

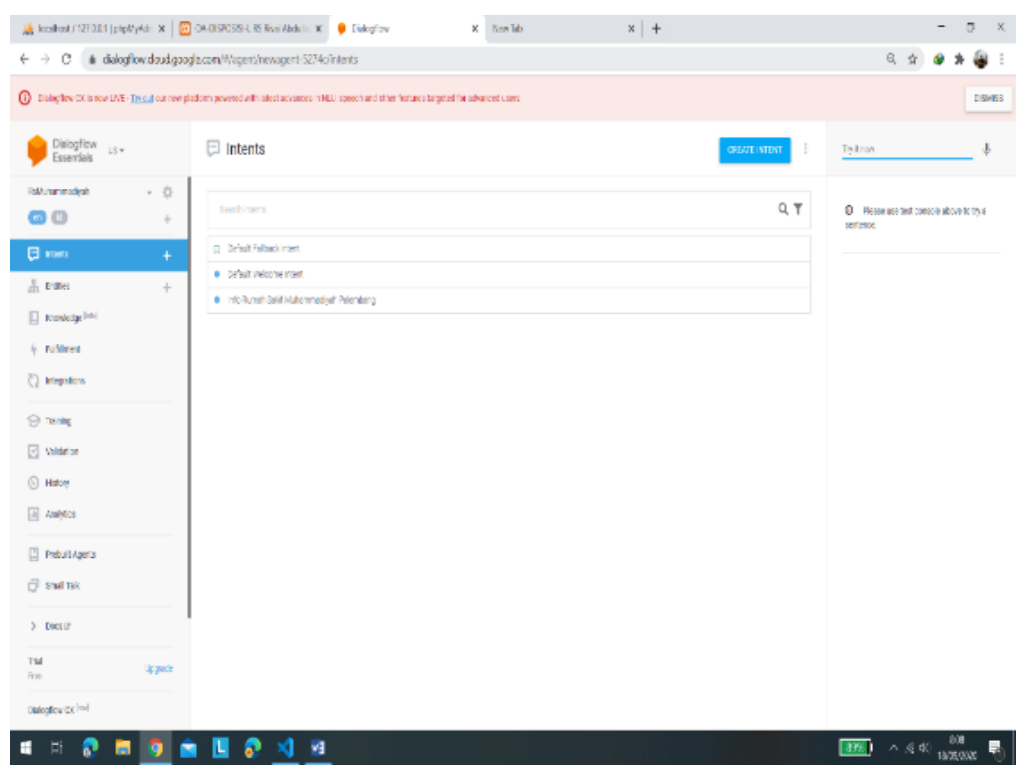




\section{Gambar 4. Halaman Intent DialogFlow}

\subsection{Halaman Fallback Intent DialogFlow}

Halaman Fallback Intent adalah halaman yang akan menampilkan jawaban ketika chatbot tidak mengerti apa yang di tanyakan oleh user.

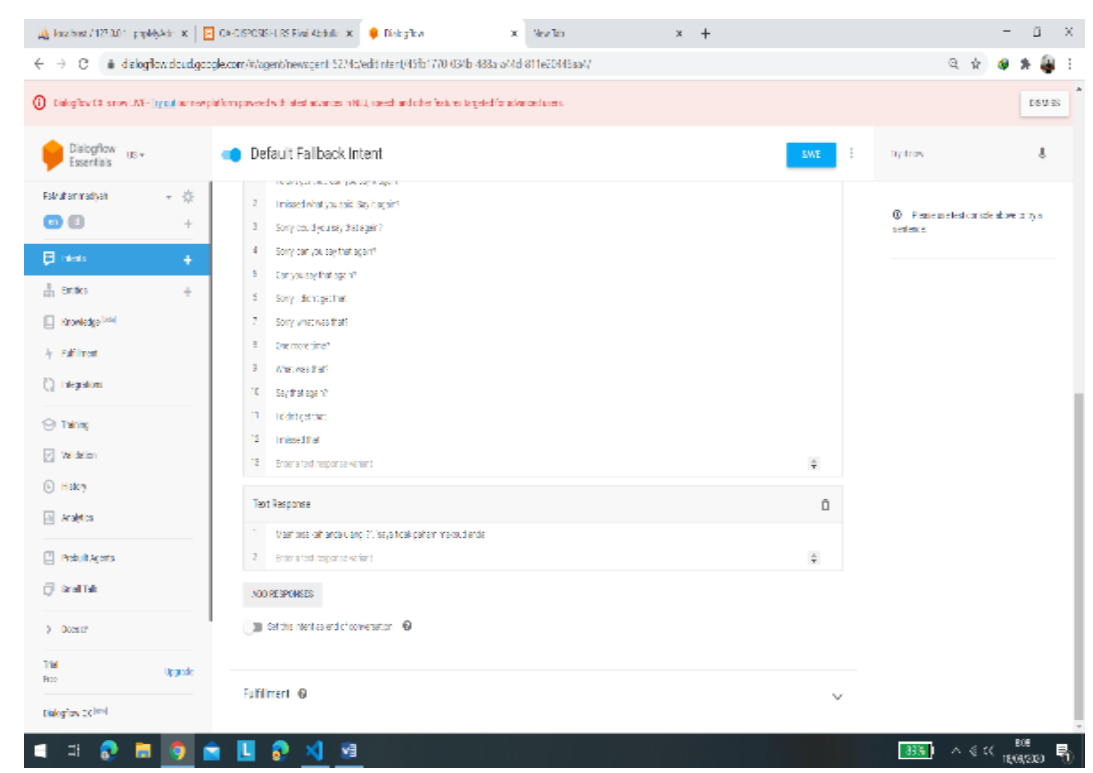

Gambar 5. Halaman Fallback Intent

\subsection{Halaman Welcome Intent}

Halaman welcome intent adalah halaman yang akan menampilkan jawaban pembukaan seperti selamat datang di sistem informasi rs muhammadiyah palembang ketika user mengucapkan hello. 


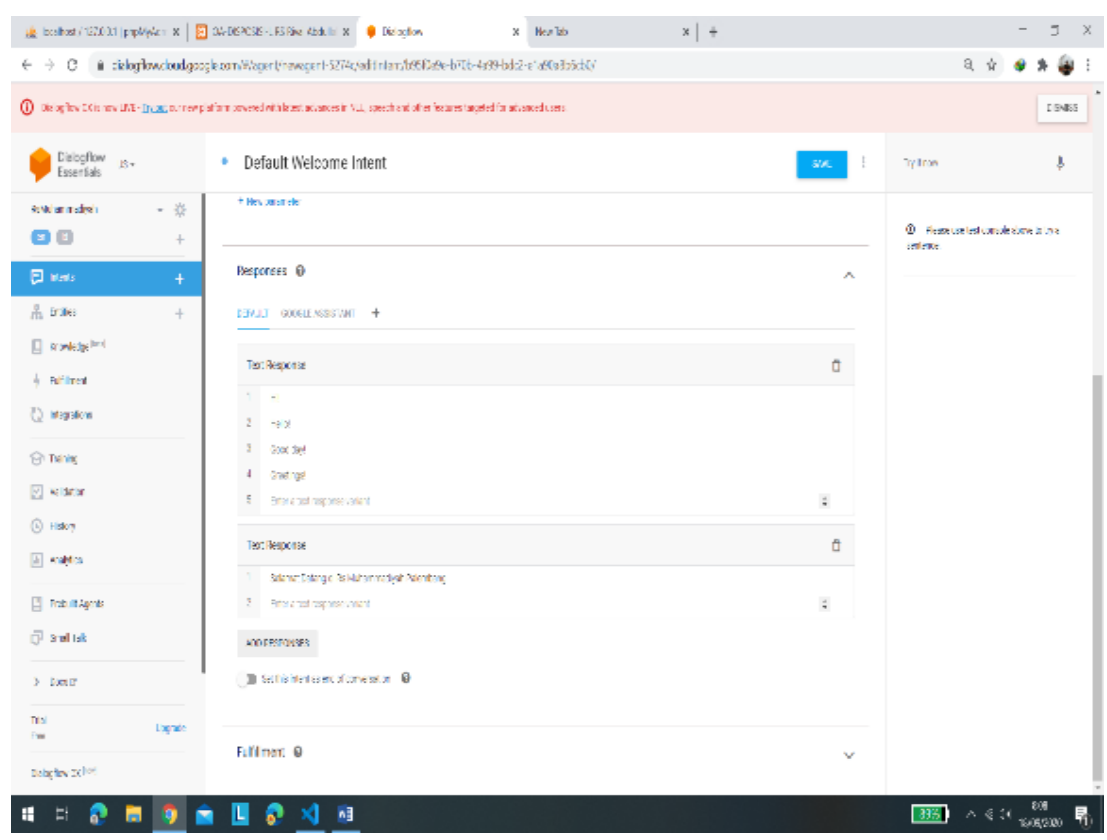

Gambar 6 Halaman Welcome Intent

\subsection{Halaman Jumlah Kamar DialogFlow}

Halaman Jumlah Kamar adalah halaman yang akan menampilkan jumlah kamar tidur yang tersedia di Rs Muhammadiyah Palembang.

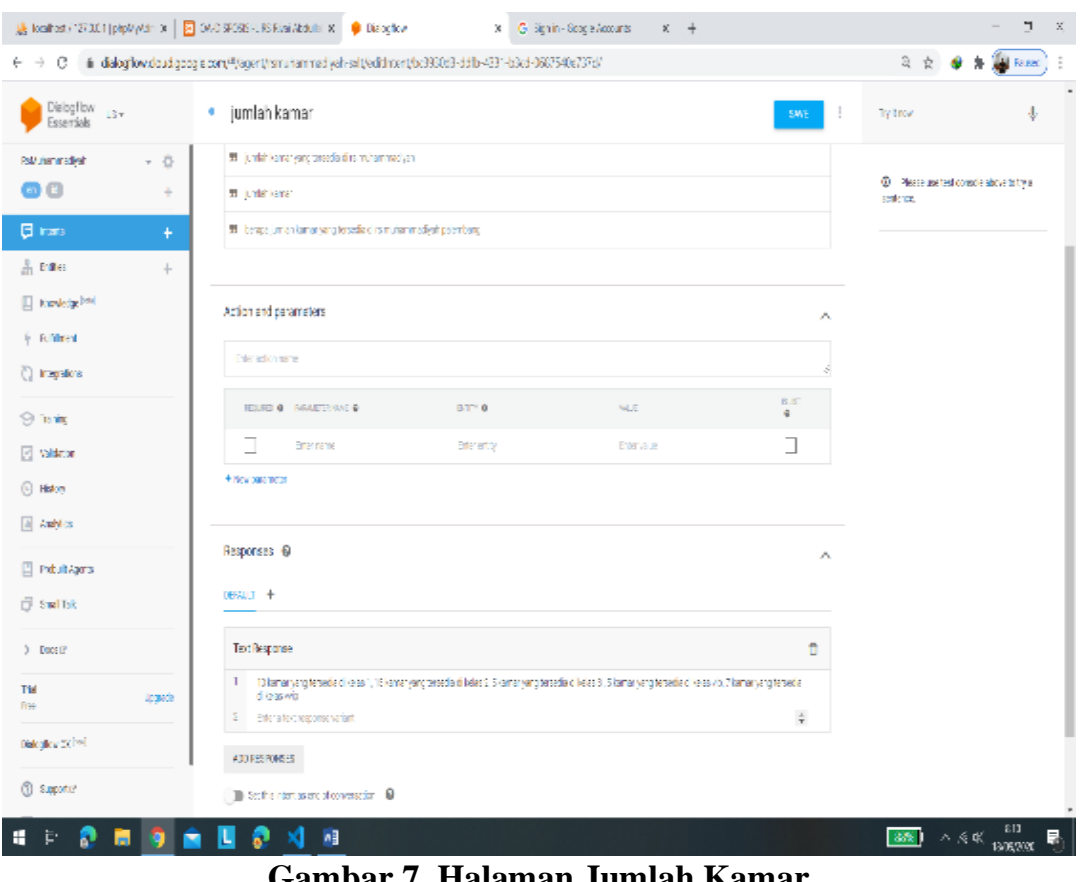

Gambar 7. Halaman Jumlah Kamar

\subsection{Halaman Jumlah Pasien DialogFlow}

Halaman Jumlah Pasien adalah halaman yang akan menampilkan jumlah pasien yang tersedia di Rs Muhammadiyah Palembang. 


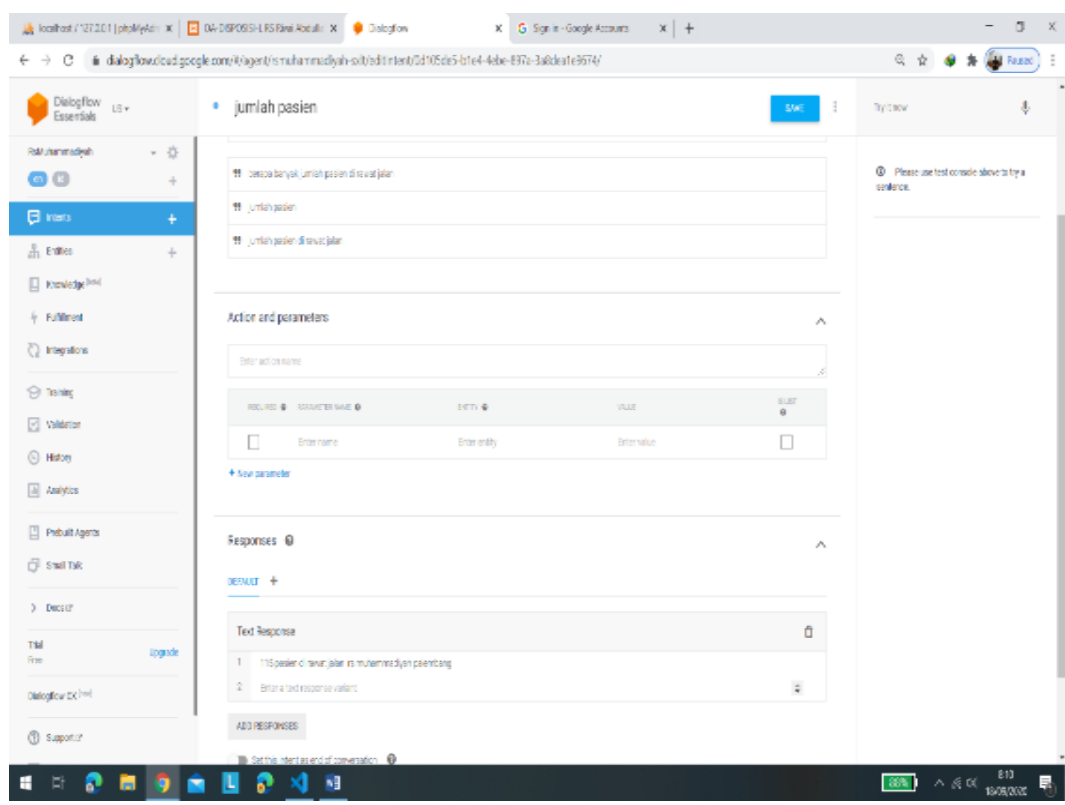

Gambar 8. Halaman Jumlah Pasien

\subsection{Halaman Lokasi Rs DialogFlow}

Halaman Lokasi Rs adalah halaman yang akan menampilkan lokasi Rs Muhammadiyah Palembang.

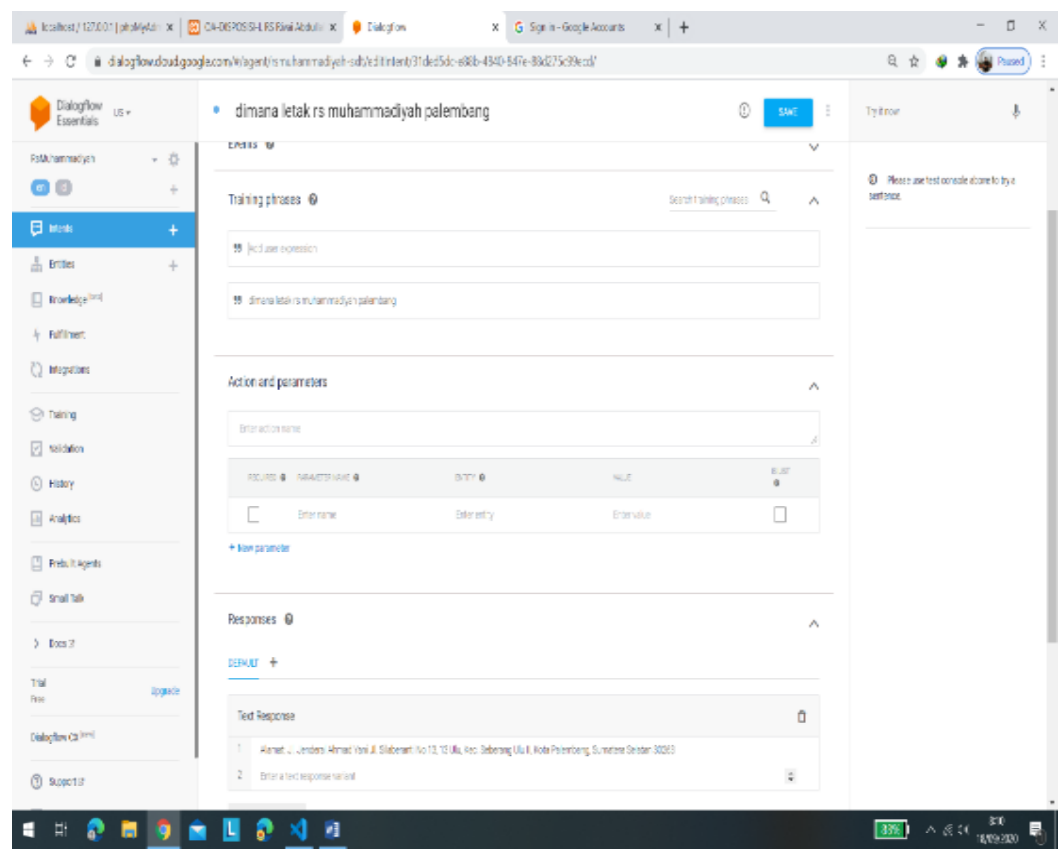

Gambar 9. Halaman Lokasi Rs.

\subsection{Halaman Pengaturan DialogFlow}

Halaman Pengaturan adalah halaman yang berfungsi untuk merubah nama chatbot di dialogflow sesuai keinginan kita. 


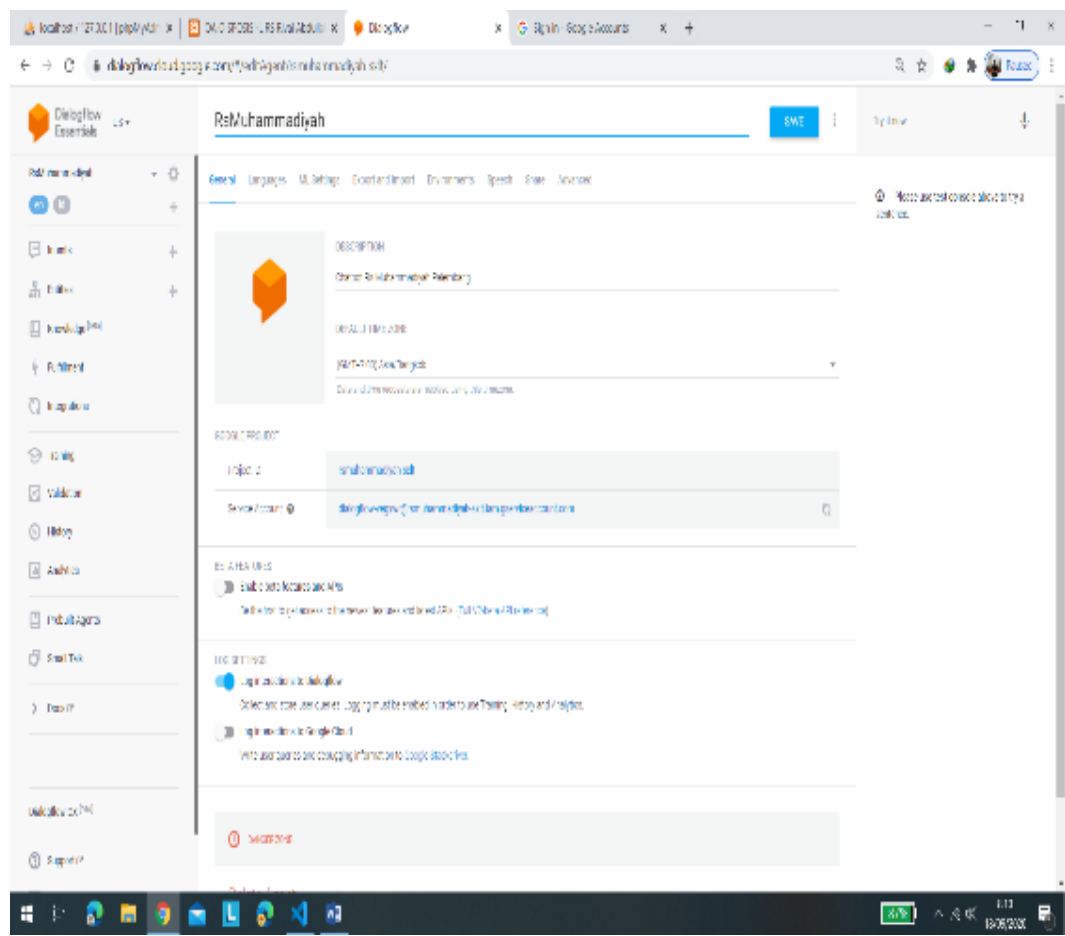

Gambar 10. Halaman Pengaturan DialogFlow.

\subsection{Halaman Chatbot}

Halaman chatbot adalah halaman yang berfungsi untuk menjawab informasi tentang rs muhammadiyah palembang ketika user bertanya bisa melalui text dan suara nanti chatbot akan merespon jawaban yang sudah kita sediakan sebelumnya di halaman DialogFlow.

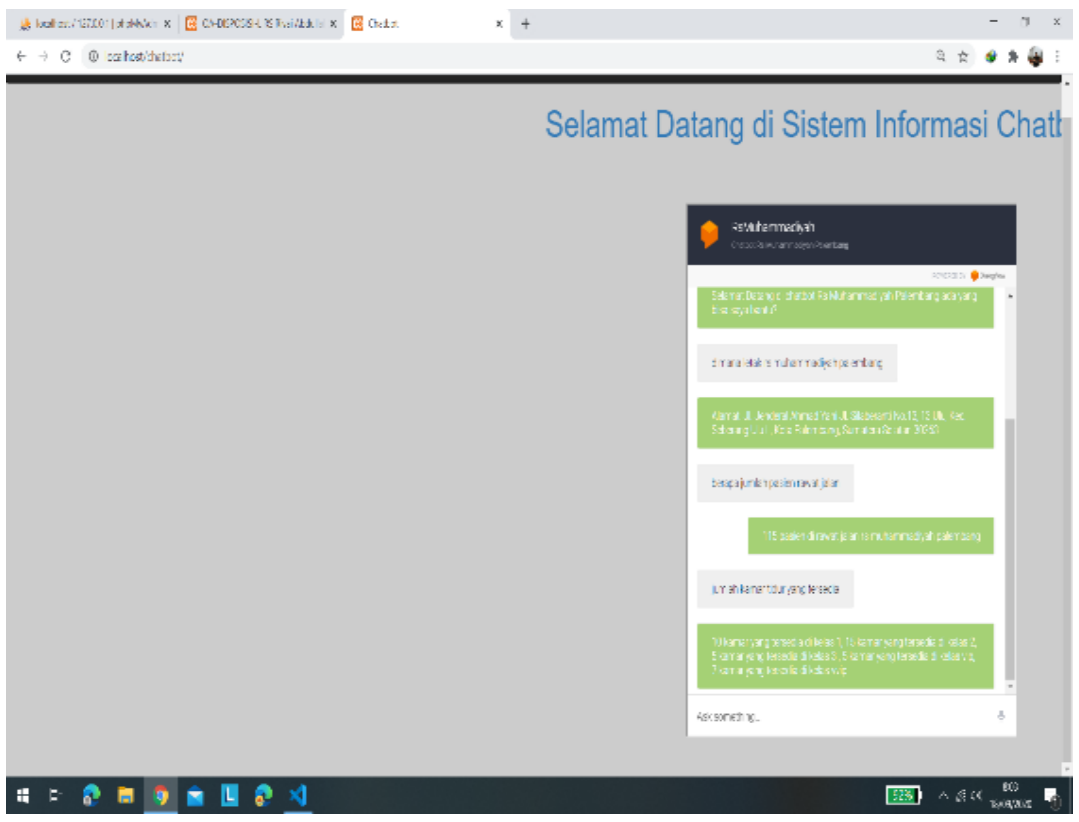

Gambar 11. Halaman Chatbot 


\section{Kesimpulan}

Berdasarkan hasil penelitian yang dilakukan terhadap implementasi chatbot pada Rumah Sakit umum muhammadiyah palembang beserta pembahasannya yang telah dilakukan, maka dapat disimpulkan bahwa:

a. Telah berhasil dibuat sistem pengelolaan pesanan untuk Rumah Sakit Muhammadiyah Palembang sesuai dengan kebutuhan rumah sakit. Sistem pengelolaan pesanan ini dapat digunakan untuk melakukan pengelolaan pesanan yang datang dari Pasien.

b. Chatbot yang dibuat untuk Pasien dapat berkomunikasi dengan menggunakan stage Flagbearer telah mampu menangani beberapa tugas percakapan yang sudah penulis rancang yaitu penanganan percakapan terhadap Pasien yang akan melakukan pemesanan produk dan juga penanganan percakapan terhadap Pasien yang akan memeriksa pesanan yang telah dibuat.

c. Chatbot telah terintegrasi dengan sistem managemen pasien di mana chatbot dapat mengakuisisi informasi dari sistem ini untuk diberikan kepada Pasien. Seperti informasi mengenai pasien”.

\section{References}

Griha, I. (2017), Perancangan Aplikasi Koperasi Simpan Pinjam Berbasis Web (Studi Kasus Koperasi Mitra Setia), Universitas Muhammadiyah, Sukabumi.

Guzman, Ines.(2016). Accenture-Chatbots-Customer-Service.Diambil kembali dari https://www.acc entur e.com /t0 0010101T000000_w_/brpt/_acnmedia/PDF45/Accenture-Chatbots-CustomerService.pdf

Nugroho, Bunafit. 2013. Dasar Pemograman Web PHP \pm MySQL dengan Dreamweaver. Yogyakarta: Gava Media

Simarmata, Janner dan Imam Paryudi. 2007. Basis Data. Yogyakarta: CV. Andi Offset.

Sibero, Alexander FK. 2013. Web Programming Power Pack. Yogyakarta: MediaKom.

Arief, M.Rudianto. 2011. Pemrograman Web Dinamis Menggunakan Php dan Mysql. Yogyakarta: ANDI.

Hend. 2006. Unified Modelling Language. Tangerang : Raharja Enrichment Centre (REC).

S, Rosa dan Shalahuddin, M. (2014). Rekayasa Perangkat Lunak Terstruktur dan Berorientasi Objek. Bandung: Informatika

Usman, Nurdin. (2002). Konteks Implementasi Berbasis Kurikulum. Jakarta: Raja Grafindo Persada.

Maskur, 2016. Perancangan Chatbot Pusat Informasi Mahasiswa Menggunakan AIML Sebagai Virtual Assistant Berbasis Web,Universitas Muhammadiyah Malang, Malang

Usman, Nurdin. (2002). Konteks Implementasi Berbasis Kurikulum. Jakarta: Raja Grafindo Persada. Metode Penelitian action research, Diakses 21 Febuari 2018, dari https://chandrax.wordpress.com/2008/07/05/action-research-penelitian- tindakan/.

Pratama, E. (2014), Sistem informasi dan Implementasinya, Informatika Bandung, Bandung 